\title{
La utopía kantiana de la comunidad ética
}

\author{
JULIO DE ZAN \\ Unsam, Uner, Conicet
}

RESUMEN. Este artículo propone una relectura contemporánea de los textos de La Religión dentro de los límites de la mera razón en los cuales Kant esboza la idea de una comunidad ética universal. Esta idea kantiana se puede parangonar con las ideas de otros pensadores de la Ilustración, que anticiparon la emergencia de nuevos sujetos sociales cosmopolitas diferentes del sujeto político encuadrado en las estructuras formales del Estado moderno, los cuales no se plantean fines directamente políticos, pero en cuanto tienen presencia en el espacio público, adquieren también una relevancia política significativa. La comunidad ética, sin la cual no podríamos ser personas morales, es para Kant algo ya existente, como comunidades informales, particulares, fragmentadas, e independientes del sistema de las instituciones jurídico-políticas. Se trata de hacer reflexivos los fines morales de estas comunidades para que puedan abrirse a la unidad de todo el género humano. La significación de esta idea kantiana se redescubre y se puede valorar más adecuadamente recién hoy, en el contexto de los debates actuales de la filosofía política, a partir del descentramiento del Estado y del retorno de la sociedad civil, o de la recuperación de su autonomía, y de las redes de integración que significan formas de globalización alternativas.

Palabras clave: utopía, Kant, filosofía política, cosmopolitismo, comunidad ética
ABSTRACT. This article proposes a contemporary revisiting of the texts of Religion within the Limits of Bare Reason in which Kant outlines the idea of a universal ethical community. The author holds it that it is possible to approach or to confront this kantian idea with the ideas of other thinkers of Enlightenment who anticipated the emergence of new cosmopolitan social subjects different from the political subject framed within the formal structures of the modern State and which, even when they do not constitute themselves with truly political aims, acquire a significant political relevance of first order, as soon as they attain presence in the public space. The ethical community, without which we could not become moral persons, is in Kant's view, something already existing as informal, particular, fragmented communities and independent from the system of the juridical-political institutions. The aim is to become reflective about these communities' moral goals, so that they may open themselves up to the unity of the whole of humanity. The significance of this kantian idea is rediscovered and can be more adequately valued only today, in the context of the actual debates in political philosophy, based on the decentralization of the State and the return of civil society, or the recovery of its autonomy, and of integration nets that represent alternative forms of globalization.

Keywords: utopia, Kant, political philosophy, cosmopolitism, Ethical comunity 


\section{1. ¿Utopía o anticipación?}

En un artículo sobre el Philosophische Entwurf de Kant para La paz perpetua el filósofo alemán del derecho Roland Wittmannn ${ }^{1}$ discute fuertemente la interpretación de este proyecto kantiano como una utopía. Propone en su lugar la comprensión del mismo mediante otro tipo de concepto que se encuentra definido en la Crítica de la Razón Pura: el de Antizipation. Al final de la «Analítica» enuncia Kant, como una suerte de conclusión de esta parte de la Crítica, que: «La Analítica trascendental llega finalmente a este importante resultado: lo más que puede hacer a priori el entendimiento es anticipar la forma de una experiencia posible» ( $\mathrm{KrV}$ A246/B303). Este resultado aparece como un límite del uso del entendimiento, pero su importancia positiva radica en que con ello se justifica también la posibilidad de los juicios sintéticos a priori que se refieren a la forma de una experiencia posible. Podrá discutirse si el concepto de «anticipación» empleado en la doctrina de la experiencia es transferible al campo de la filosofía práctica. Pero lo cierto es que los enunciados preliminares y definitivos de los artículos del pacto para la paz perpetua anticipan precisamente algunos rasgos de una institucionalidad concreta, realizable en el tiempo; el carácter a priori de esta anticipación se deriva a su vez del concepto del derecho y del imperativo categórico que están para Kant en la base del desarrollo que debe conducir a la unificación para la paz.

R. Wittmann encuentra una fuerte contraposición entre los conceptos de anticipación y de utopía porque él trabaja con un concepto muy estrecho y negativo del pensamiento utópico ${ }^{2}$, pero, no obstante esta observación, hay que admitir que su interpretación del método de Kant en el mencionado opúsculo resulta plausible. Este punto de vista se corrobora además teniendo en cuenta especialmente que, si bien la idea kantiana de la restricción recíproca de la soberanía de los Estados mediante pactos internacionales, con los cuales se crearía un derecho de gentes de vigencia efectiva para la paz perpetua, pudo parecer utópica en la época de la soberanía absoluta de los Estados modernos, durante el transcurso del siglo xx esta soberanía se ha visto severamente cuestionada en la teoría política, limitada en los hechos particularmente después de las dos guerras mundiales y rebasada en el proceso de la globalización que produce una creciente interdependencia de los pueblos; y la idea kantiana ha tenido un significativo principio de realización.

Pero los argumentos mencionados contra el carácter utópico del escrito kantiano sobre La paz perpetua no son aplicables, sin embargo, a esta otra

1 Wittmann, R., «Kants Friedenentwurf -Antizipation oder Utopie?», en «Zum ewigen Frieden», Grundlagen, Aktualität und Ausssichten einer Idee von Immanuel Kant, Hrsgg. von V. R. Merkel y R. Wittmann, Frankfurt, Suhrkamp, 1996, pp. 142-153.

2 Una visión más comprensiva de la función del horizonte utópico en la filosofía de Kant es la que expone Roberto R. Aramayo, Crítica de la razón ucrónica, Madrid, Tecnos, 1992. 
idea de la razón práctica de la que voy a ocuparme en este trabajo: la comunidad ética universal. Más bien a la inversa, el argumento anterior se puede dar vuelta en sentido contrario, porque la posibilidad de interpretar el método de exposición de esta idea, conforme al concepto de la «anticipación de una experiencia posible» de la Crítica de la Razón Pura, ha sido excluida de manera expresa por el propio texto kantiano:

Una comunidad ética bajo la legislación moral divina es una iglesia que, en cuanto no es objeto de ninguna experiencia posible, se llama iglesia invisible (una mera idea de la unificación de todos los hombres probos...) (Relig. 760;126) ${ }^{3}$.

\section{La idea de una comunidad ética}

En el escrito de 1793 sobre La religión dentro de los límites de la mera razón, se refiere Kant en su primera parte a la presencia de un principio del mal que, junto al bien, está arraigado en la propia naturaleza del hombre: el «mal radical» ${ }^{4}$. Según ha escrito $\mathrm{H}$. Arendt en las observaciones finales a su libro sobre Los orígenes del Totalitarismo, al acuñar este concepto de un mal radical en el hombre, Kant ha entreabierto la puerta de un abismo inquietante e inescrutable de la condición humana, que cuestiona toda la tradición humanista del pensamiento occidental; pero él ha intentado racionalizarlo de nuevo en seguida de manera comprensible y asimilable dentro de esta tradición. Si bien la propensión a la maldad (Hange zum Böse) está dada de manera innata (angeborene) como una posibilidad humana, el ceder a ella, y asumirla, es una elección del libre albedrío. La realidad del mal no tiene, por lo tanto, su origen en la naturaleza, o en el cuerpo y en las inclinaciones sensibles; solamente el libre arbitrio (el Willkür) puede producirlo y hacerse a sí mismo efectivamente malo. Pero por esto mismo, hasta el más malvado de los hombres puede también, mediante «una transformación del corazón», adoptar en su libertad una nueva disposición interior (Gesinnung) y reemplazar las máximas malas de su conducta por otras buenas, aunque la propensión al mal permanezca inextirpable y deba luchar siempre contra ella, buscando los apoyos necesarios para sobreponerse. Este problema antropológico y metafísico del mal ha dado lugar a interpretaciones divergentes porque los textos de Kant no están exentos de ambigüedades 5 .

${ }^{3}$ Los números de página entre paréntesis remiten en primer lugar a I. Kant, Werkausgabe VIII, Frankfurt, Suhrkamp, 1991; y en segundo término a la traducción castellana de F. Martínez Marzoa, I. Kant, La Religión dentro de los límites de la mera Razón, Madrid, Alianza, 2001. La traducción de los textos citados ha sido revisada y modificada en algunos casos.

${ }^{4}$ Sobre este problema general quiero remitir aquí solamente al reciente libro de R. Bernstein, El mal radical, Bs. As., Lilmod, 2004.

${ }^{5} \mathrm{La}$ reflexión sobre las tragedias del siglo XX, como los genocidios, las grandes guerras mundiales, la situación social de pobreza y de hambre de grandes regiones del mundo en medio de la 
Después de tratar en la Segunda Parte la lucha del principio del bien con el mal en el hombre, se ocupa en la Tercera de cuál es la condición necesaria para que el bien pueda triunfar. El comienzo de esta Tercera Parte del texto de la Religión plantea en cierto modo una doble paradoja. Por un lado, sostiene que la propensión al mal es innata e inextirpable y, en este sentido, hay que decir que «el hombre es por naturaleza malo»; por otro lado, explica, sin embargo, que no es el hombre solitario, que vive aisladamente, el que se ve arrastrado por esta propensión al mal, sino que las circunstancias que despiertan la maldad en el hombre provienen de la vida social, aunque en un sentido diferente de Rousseau, y más próximo a Hobbes.

«La envidia, el ansia de dominio, la codicia, y las inclinaciones hostiles que se derivan de todo ello, se apoderan de su naturaleza, en sí modesta, tan pronto como está entre [otros] hombres (wenn er unter Menschen ist); no es necesario presuponer tampoco que éstos [los otros] están ya hundidos en el mal y constituyen ejemplos que inducen a él; basta que ellos estén ahí, que lo circunden, y que sean hombres (es ist genug, dass sie da sind, dass sie umgeben, und dass sie Menschen sind) para corromperse mutuamente en sus aptitudes morales, y hacerse malos unos a otros (sich einander böse zu machen)» (Relig. 751-52; 118).

La otra paradoja, que se suma a la anterior, es que el individuo sólo no puede tampoco dominar la propensión al mal en sus relaciones con los otros, y para mantener su fidelidad a «los deberes de virtud» necesita la ayuda, o el apoyo, de una comunidad integrada con este fin moral. Es decir, que el hombre solitario, en la situación robinsoniana, fuera de la sociedad, no tiene cómo ser malo; pero si permanece sólo, o aislado dentro de la sociedad, difícilmente puede ser bueno. Para el desarrollo de la moralidad en las relaciones con los otros el hombre tiene que asumir una identidad moral intersubjetivamente reconocida, como miembro de un nosotros. En el lenguaje de Kant esto es «una unión de hombres bajo meras leyes de virtud», a la cual se le ha de llamar: «una comunidad ética (ein ethisches gemeines Wesen)» (Relig. 751-752; 118).

Para explicar la necesidad de la formación de la comunidad ética se vale Kant de una analogía con la situación en que se encontrarían los hombres, según la descripción de Hobbes, si no existiera un ordenamiento jurídicopolítico y ningún poder soberano capaz de hacer respetar coactivamente las leyes civiles, el «status belli» de todos contra todos, que Kant precisa ahora como: «estado de naturaleza jurídico». De manera semejante hay que pensar la situación de los hombres mientras no se integren al mismo tiempo en una comunidad ética de personas morales, como un «estado de naturaleza ético», en el cual los individuos están expuestos e indefensos frente a las incesantes

opulencia de las sociedades centrales, replantea hoy de manera fuerte el problema del mal radical señalado por Kant. 
acechanzas del principio del mal, y se transforman, a su vez, en sus instrumentos.

Las normas de la virtud de esta comunidad deberían armonizar con las leyes jurídicas de la sociedad civil, pero son enteramente diferentes. Hay por lo menos cuatro propiedades fundamentales que hacen esta diferencia (cfr. Relig. 757; 127). 1) La universalidad de esta comunidad, que debe extenderse a todo el género humano, independientemente de las diferencias contingentes de los pueblos. De hecho la extensión de la comunidad ética puede ser menor o mayor que la de la sociedad civil, pero de acuerdo a su propio fin la idea de esta comunidad debe tender a una asociación universal de la humanidad en cuanto tal. 2) Los motivos de esta unión son puramente morales. Esta pureza de intención implica que se prescinde aquí tanto de los fines empíricos, o de todo otro tipo de intereses, como de las exaltaciones del sentimiento o de la superstición («Gereignit vom Blödsinn des Aberglaubens und dem Wahnsinn der Schwärmerei»). 3) La libertad, tanto interna, en las relaciones de sus miembros entre sí, como externa, frente al poder público. Los individuos no se unen en esta comunidad, como en la sociedad civil, renunciando a su libertad (o a parte de ella) con el fin de constituir un poder soberano que atemorice a todos y los proteja de peligros externos a ellos mismos. El enemigo a vencer es la propia propensión al mal, y el tipo de coacción de las leyes de virtud es puramente interior. Además, la adhesión a una comunidad ética, y la permanencia en ella, deben ser siempre voluntarias. 4) La inmutabilidad de sus principios, que expresan obligaciones morales necesarias y que han de permanecer independientes de las previsiones contingentes de toda organización conforme a las circunstancias cambiantes de tiempo y lugar. El Prefacio a la $1 .^{a}$ edición de La Religión comienza con el recuerdo de que: «La moral se funda en una concepción del hombre como ser libre que, a través de la razón, se obliga sí mismo por medio de leyes incondicionales [y puede hacerlo precisamente porque es libre y racional] (Relig. 649; 21).

\section{La comunidad frente al sistema jurídico-político}

Si bien la comunidad ética, tal como la concibe Kant, «se diferencia esencialmente en su forma y en su constitución» de la sociedad política, no sólo existe de hecho en medio de ella, sino que no podría constituirse en absoluto si no es sobre la base y en el contexto del Estado de Derecho de la sociedad civil; el presupuesto de la comunidad ética es ein rechtlichbürgerlischer (politischer) Zustand. Conforme al texto de La paz perpetua, la existencia y el funcionamiento del sistema jurídico-político, con sus leyes coactivas, no presupone, en cambio, que los ciudadanos en cuanto tales sean de hecho también morales, y no puede presuponer tampoco, por lo tanto, la unión de 
sus miembros como comunidad ética. En el texto de La Religión se reafirma ese mismo pensamiento al decir que, de hecho, aunque en las sociedades políticas existentes ya se ha salido del estado de naturaleza jurídico, «todos los ciudadanos políticos en cuanto tales se encuentran en estado de naturale$z a$ ética» (Relig. 754; 120). Creo que esta afirmación no debería interpretarse en sentido meramente descriptivo, o crítico de la sociedad europea contemporánea (aunque también puede tener en parte este sentido), sino más bien como referida a la diferencia, y a la independencia de estos dos tipos de asociación humana en general.

Lo que le interesa destacar a Kant en este contexto es sobre todo que sería contradictorio, tanto con el concepto de lo jurídico como con el de la propia comunidad ética, que los ciudadanos fueran privados de su libertad de permanecer en el estado de naturaleza ético y coaccionados de alguna manera a ingresar en una comunidad ética, «dado que ésta, ya en su concepto lleva consigo la libertad de toda coacción», mientras que el orden jurídico es coactivo por definición, y solamente es competente sobre la conformidad externa de las acciones con el derecho, que es la legalidad. Es ciertamente deseable desde el punto de vista político que los ciudadanos se rijan por principios morales. Ya Maquiavelo había observado el problema de la gobernabilidad de un pueblo sin moral y sin religión. Pero Kant rechaza fuertemente todo paternalismo moralizante del Estado. La comunidad ética es el espacio propio de la autonomía de la conciencia moral, que es definitoria del concepto mismo de la moralidad. El texto advierte enfáticamente:

¡Ay del legislador que quisiera poner en vigencia de manera coactiva una constitución dirigida hacia fines éticos! Porque con ello no sólo produciría precisamente lo contrario de algo ético, sino que terminaría por socavar y hacer insegura la propia constitución política... Aquellos que libremente se unen para entrar en este estado [de la comunidad ética] no tendrán que dejarse ordenar por el poder político cómo deben disponer o no disponer interiormente las leyes de esta comunidad, pero sí tendrán que tolerar restricciones, a saber: con arreglo a la condición de que nada haya en ella que esté en conflicto con el deber de sus miembros como ciudadanos del Estado; de todos modos, si esta unión es de índole genuinamente ética este último no tendría nada de qué preocuparse» (Relig. 754; 120).

La última observación del autor está obviamente destinada a tranquilizar al Príncipe para que desista de intervenir en esta esfera. Pero es claro que el Estado tiene mucho de qué preocuparse, porque una comunidad ética autónoma, aunque respetuosa de las leyes jurídicas, representa un control y una restricción muy fuerte frente a las posibles arbitrariedades e injusticias del poder estatal. Una comunidad vigorosa de este tipo es, por su sola presencia en el espacio público de la sociedad civil, un contrapoder moral que el Príncipe no puede dejar de respetar y tener en cuenta en sus decisiones. 
La relación entre la comunidad ética y el orden jurídico-político del Estado es, según hemos visto, al mismo tiempo de inclusión de la primera en la segunda, y de entera autonomía, como la separación de la Iglesia y del Estado. La comunidad ética no podría existir sin la protección y la garantía del Derecho, pero tampoco sin su independencia frente al poder político. Parece que esta relación será fuente de inevitables tensiones y conflictos, sobre todo si tenemos en cuenta, en primer lugar, que la comunidad ética es una asociación voluntaria pero no meramente privada, como la familia, sino que su constitución, sus principios, y la dinámica de la vida comunitaria han de ser públicas, en cuanto reconocidas por todos sus miembros y expuestas a la luz pública de la sociedad civil. Y en segundo lugar, es preciso tener en cuenta que esta comunidad está inscripta dentro del Estado, pero, a su vez, por su misma naturaleza, lo trasciende y tiende a adquirir un alcance universal, o cosmopolita, lo cual incremente su poder espiritual frente al poder político. Si bien el propio Kant no explicita aquí estas consecuencias polémicas en su contexto (hay que recordar que el texto tuvo bastantes dificultades con la censura) debemos presuponer que él no era inocente sobre las limitaciones a la soberanía que implicaba su doctrina y que lo ponía en este punto en las antípodas del absolutismo hobbesiano.

Desde el punto de vista político-estratégico de Hobbes lo único que hay que decir del estado de naturaleza jurídico es que hay que salir de él lo más pronto posible, o perecer. Ya este «hay que» tiene también para Kant el valor agregado de un deber moral de buscar la unificación con los demás hombres en la sociedad política. De manera análoga, afirma Kant, hay que salir del estado de naturaleza ético, pero esta necesidad tiene ahora el significado de un deber moral puro de pertenencia a la comunidad ética de los seres racionales como la condición necesaria de la propia identidad moral. En su filosofía política Kant sigue a Hobbes todavía un paso más, al explicar también la forma de la constitución del Derecho y del Estado (como las construcciones políticas que reemplazan al estado de naturaleza) por medio de la figura del contrato. Pero en esta otra dimensión abandona enteramente las categorías hobbesianas, que son impertinentes para describir la constitución de la comunidad ética, o el «lugar» donde debemos arribar si queremos salir del estado de naturaleza ético, y recurre a otra analogía que se vincula con el tema propio de este libro sobre la Filosofía de la Religión: «Una comunidad ética sólo puede ser pensada como un pueblo bajo mandamientos divinos, esto es: como un pueblo de Dios gobernado solamente por leyes de virtud» (Relig. 760; 126).

La estrategia de servirse del modelo de la separación de la Iglesia y del Estado, así como de redescribir al mismo tiempo a la primera como una «Iglesia invisible», que se diferencia de las iglesias estatutarias, o institucionales, y cuyo contenido es esencialmente el de la moralidad, tiene un doble efecto: a) otorga a la autonomía de la comunidad ética un respaldo superior, 
o divino frente al poder político, y ayuda a subordinar la legalidad a la moralidad; $b$ ) el análogon (la iglesia invisible) se sobrepone al analogado originario (las iglesias históricas, visibles y estatutarias) y tiende a reemplazarlas, o a diluirlas a largo plazo en la comunidad ética universal.

\section{La universalidad cosmopolita de la comunidad ética}

Kant da a entender que la comunidad ética no es una mera idea, sino algo que es ya real y existente de algún modo en la sociedad civil. Pero aclara, sin embargo, que «un conjunto de hombres unidos con esta intención moral [es decir: una pequeña comunidad de amigos morales] no puede considerarse todavía como la comunidad ética misma, sino como una asociación particular», que se orienta en el sentido de dicha comunidad, y que puede estar abierta y en conexión con otras asociaciones del mismo género, pero a su realidad les falta todavía la nota esencial de la universalidad comprensiva de todo el género humano. Es claro, en cambio, que esa totalidad, «como república universal según leyes morales», es una idea de la razón a la que no corresponde algo realmente existente, ni sabemos si está en nuestro poder alcanzarla y, en cualquier caso, no es «nunca plenamente alcanzable». Esto es lo que diferencia precisamente a una «simple idea» en el uso especulativo de la razón, de la idea de la razón práctica, a saber: que esta última «puede darse siempre en concreto, de modo real, aunque sólo parcialmente. Es más, tal idea constituye la condición indispensable de todo uso práctico de la razón» ( $\mathrm{KrV}$ A 328). Obrar en orden a la meta señalada por esta idea regulativa de la comunidad ética universal es para Kant «un deber moral irrenunciable del género humano para consigo mismo», aunque este fin no se logre más que de manera aproximativa.

Hay que decir, en definitiva, que existen muchas comunidades éticas particulares, sin las cuales los individuos no podrían ser morales, pero que la idea regulativa conforme a la cual se constituyen estas comunidades de amigos morales, o el telos al que debe orientarse su obrar, es para Kant la comunidad ética universal del género humano. Y habría que agregar todavía que, sin esta apertura universalista, las comunidades particulares cerradas sobre sí mismas pierden incluso todo sentido moral.

Puesto que los deberes de virtud conciernen a todo el género humano, el concepto de una comunidad ética estará siempre referido al ideal de una totalidad de todos los hombres; en esto se diferencia del concepto de una comunidad política. Esta idea tiende a la unanimidad con todos los hombres... para fundar un todo ético absoluto, del cual cada asociación particular es solamente una representación, o un esquema... (Relig. $755 ; 121$ ). 
En esta otra dimensión ya no contractual ni juridizable del ideal cosmopolita, podría decirse que el mundo actual ha avanzado más que en la confederación de Estados para la paz perpetua, a través de las organizaciones de derechos humanos, los movimientos sociales trasnacionales del feminismo, de la defensa del medio ambiente, de la lucha contra la pobreza y el hambre en el mundo y los foros universales para los más diversos temas de interés común humano, etc., que constituyen esbozos de una sociedad civil cosmopolita, la cual se tiene que enfrentar, al mismo tiempo, con la soberanía política de los «intereses nacionales» de los Estados, y con la irracionalidad de la globalización del sistema económico financiero ${ }^{6}$.

Puede pensarse que la idea de la comunidad ética universal del género humano es una utopía, y efectivamente lo es si entendemos esta palabra en su sentido literal, porque no designa nada empírico existente en algún lugar. Pero frente al pesimismo escéptico que pretende desacreditar toda forma de pensamiento utópico, quiero traer un pasaje de la Crítica de la Razón Pura, cuando explica la función de las ideas de la razón en general, y se refiere a modo de ejemplo al ideal normativo de una constitución política republicana «que promueva la mayor libertad humana». Aunque Kant no hubiera pensado todavía la idea de la comunidad ética universal cuando escribía la primera Crítica, sus expresiones se aplican especialmente a ella. Después de esbozar el pensamiento de esta constitución, agrega el siguiente comentario:

Esto es, como mínimo, una idea necesaria, que ha de servir de base no sólo al proyecto de una constitución política, sino a todas las leyes. Por eso debe hacerse abstracción desde el comienzo de los obstáculos actuales... En efecto, nada hay más pernicioso e indigno de un filósofo que la plebeya apelación a una presunta experiencia contradictoria [con una idea de la razón]... Aunque no llegue a producirse nunca, la idea que presenta ese máximum como arquetipo es plenamente adecuada para aproximar progresivamente la constitución jurídica de los hombres a la mayor perfección posible. En efecto, nadie puede ni debe determinar cuál es el supremo grado en el cual tiene que detenerse la humanidad, ni, por tanto, cuál es la distancia que necesariamente separa la idea y su realización. Nadie puede ni debe hacerlo porque se trata precisamente de la libertad, la cual es capaz de franquear toda frontera predeterminada ( $\mathrm{KrV}, \mathrm{A} 316-17, \mathrm{~B} 373-74)$.

En este bello texto aparecen claramente destacados algunos rasgos significativos del pensamiento utópico de Kant, aunque el autor no use aquí el concepto de «utopía». 1) No se trata de meros conceptos del entendimiento, sino de ideas que explicitan exigencias necesarias de la propia razón prácti$\mathrm{ca}$, las cuales se contraponen, por lo menos en parte, a la facticidad de lo dado en la experiencia. 2) No se trata, sin embargo, de meras construcciones

- Cfr. J. de Zan, «Un estado de derecho común en el mundo», en Diálogo político, Revista de la Konrad Adenauer Stiftung, núm. 31, Buenos Aires, 2004, pp. 29-60. 
ficcionales desconectadas de toda realidad, sino de la maximización intensiva y de la ampliación de elementos o principios ya existentes y operantes (de una manera que podríamos llamar seminal) en el mundo de la vida, y que hay que hacer germinar. 3) Para pensar como posibles estas ideas en sí mismas hay que hacer abstracción primero intelectualmente de las determinaciones que aparecen como datos empíricos que las contradicen, o como obstáculos a remover en el mundo para su realización; y luego vencer en la praxis las resistencias para el desplazamiento de estos obstáculos. 4) Es tarea propia del pensar filosófico precisamente elevarse más allá de la facticidad del mero empirismo de lo dado. La chatura del empirismo, que prohíbe pensar y se mantiene esclavo de lo que hay, es lo más pernicioso y merece el mayor desprecio porque desconoce o pretende anular la libertad del pensamiento y de la acción. «Nada hay más pernicioso e indigno de un filósofo que la plebeya apelación a una presunta experiencia contradictoria con las ideas de la razón». 5) Las ideas de la razón práctica no son meros pensamientos teóricos, o ficciones de la imaginación, sino que comprenden y expresan el sentido de una tendencia, o aspiración existente, y no meramente accidental. Por esta razón se tienen que comprender como orientaciones para la acción, y establecen las bases o arquetipos para el proyecto de la propia constitución política. 6) «La distancia que separa la idea de su realización» indica que no se trata solamente de vencer los obstáculos del estado actual de cosas que se oponen al ideal, sino también de una tarea positiva de construcción de realidad. Si se puede hablar de pensamiento utópico en Kant, hay que aclarar que él no piensa ni en la creación de algo absolutamente nuevo, ni en la mera transformación revolucionaria de lo existente, sino en la posibilidad de un proceso evolutivo gradual en el horizonte teleológico de las ideas de la razón. 7) El máximum de la realización plena del ideal de la comunidad ética universal del género humano quizás no llegue a realizarse nunca, pero la posibilidad y los límites de su realización dependen fundamentalmente de la propia libertad de los hombres, la cual puede siempre sorprendernos. El pesimismo histórico y el realismo anti-utópico desconocen la infinitud intencional de la libertad, o niegan su propia existencia. «Nadie puede ni debe determinar cuál es el supremo grado en el cual tiene que detenerse la humanidad, ni, por tanto, cuál es la distancia que necesariamente separa la idea y su realización. Nadie puede ni debe hacerlo porque se trata precisamente de la libertad, la cual es capaz de franquear toda frontera predeterminada».

En el escrito Erneuerte Frage... sobre el progreso moral del género humano, se refiere Kant a las utopías de Platón y de Th. Moro, entre otras, y considera estos escritos como creaciones (Staatschöpfungen) o narrativas de acontecimientos en los cuales, como en la creación del mundo, ningún hombre pudo estar presente, y que no pueden ser pensadas tampoco como plenamente realizadas en un futuro, por más lejano que se lo imagine, «pero el 
aproximarse siempre [a este horizonte utópico] es no solamente pensable, sino que, en tanto en que ello es compatible con las leyes morales, constituye un deber» ${ }^{7}$.

$\mathrm{Si}$ atendemos al contenido de la comunidad ética, más allá de la letra del texto, no se trata por cierto de una comunidad propiamente religiosa. Kant excluye expresamente de esta «Iglesia» todo tipo de cultos, de ministerio religioso y de jerarquías de tipo eclesiástico: «no tiene servidores legales como funcionarios de la comunidad ética... tendrá como servidores (pero sin que sean funcionarios) a todos los hombres de buenos pensamientos» (Relig. 820 y $821 ; 185$ ). Sin embargo, la idea de la unión de todos los hombres en una comunidad puramente moral, como «un reino de Dios sobre la tierra», aparece como una utopía inalcanzable para el hombre mismo. Sólo cabe la esperanza de su plena realización como la obra de «un soberano moral del mundo». Sabemos que la esperanza, también para Kant, como para la teología, está ligada a la fe, pero para el filósofo la esperanza verdadera es la que se funda en una fe racional ${ }^{8}$. El uso kantiano de todo este léxico de la «fe», de la «esperanza», y del «reino de Dios», que él toma de la teología, se puede leer hoy también en clave de pensamiento utópico. La significación literal del lenguaje teológico se encuentra estrechamente acotada mediante la expresa exclusión de figuras como las de los intérpretes privilegiados, representantes, o ministros humanos del pensamiento, o de la voluntad divina. $Y$ como tampoco es pensable, por supuesto, algún tipo de intervención directa, o milagrosa, de Dios mismo en persona, a los fines concretos de la praxis no queda más que la pura razón práctica y la buena voluntad moral de los propios miembros de la comunidad.

Quiero cerrar este punto con tres breves párrafos del texto que dejan abiertas diferentes interpretaciones posibles. «Es una expresión absurda la de que los hombres puedan instituir un reino de Dios (tal como puede decirse de ellos que pueden erigir un reino de un monarca humano). Tiene que ser Dios mismo el autor de su reino» (Relig. 820; 184). «Instituir un pueblo de Dios moral es, por lo tanto, una obra cuya ejecución no puede esperarse de los hombres, sino sólo de Dios mismo. Con todo, no está permitido al hombre permanecer inactivo respecto a este negocio y dejar que actúe la Providencia... Más bien ha de proceder como si todo dependiera de él, y sólo bajo esta condición puede esperar que una sabiduría superior concederá a sus bienintencionados esfuerzos la consumación» (Relig. 760; 126). «La idea de un soberano moral del mundo es una tarea para nuestra razón práctica» (Relig. 806; 172).

\footnotetext{
${ }^{7}$ I. Kant, Erneuerte Frage: ob das menschliche Geschelcht im beständige Fortschreiten zum besseren sei, en Kants gesammelte Schriften Hrsgg, Berlin, von der Königlich Preubischen Akademie der Wissenschaften, 1907, 17, VII, reimpreso en Ed. W. de Gruyter, Berlin, Akademie Textausgabe, 1968, VII, p. 92 (nota de Kant al pie de página).

8 Sobre este concepto de «fe racional», cfr. R. Rodríguez Aramayo, «El bien supremo y sus Postulados. (Del formalismo ético de Kant a la fe racional)», en op. cit., nota 2, pp. 59-113.
} 


\section{La formación de la comunidad ética}

Si nos preguntamos cómo es posible pensar la formación de la comunidad ética, de acuerdo a lo que ha sido dicho en los puntos anteriores tiene que quedar claro, por lo menos negativamente, que todas las explicaciones conocidas sobre el origen de la sociedad resultan inapropiadas e inaplicables en esta dimensión. a) La explicación aristotélica del origen natural a partir de la sociabilidad como propiedad esencial del hombre no es aceptable porque para Kant, como para Hobbes, de lo que se trata es, precisamente, de salir del estado de naturaleza, tanto jurídico, como ético. b) La narrativa históri$c a$, a partir de la memoria, o del relato de un acontecimiento fundacional y de las tradiciones comunes es adecuada para comprender la constitución de las comunidades, o las iglesias particulares, pero no para la comunidad ética universal. c) La teoría contractualista es adoptada por Kant para la explicación de la constitución jurídico-política del Estado, pero dejada de lado, como se ha visto, en la descripción de esta comunidad.

El concepto de contrato es explicado por el propio Kant como una formalización especial de la institución de la promesa. Representa ante todo una figura propia del Derecho privado, y en ese lugar de su Doctrina del Derecho lo analiza, y describe el vínculo contractual entre las partes, pero ya en este análisis del concepto aparece naturalmente el tercero. «Todo contrato se compone en sí, es decir, objetivamente considerado, de dos actos jurídicos: de la promesa y de la aceptación de la misma». Pero con esto sólo, advierte el autor, «no tengo todavía subjetivamente seguridad alguna» del cumplimiento de las promesas contractuales. Por lo tanto, se requiere algo más para la certeza de los contratos. «Con vistas a tal fin entran en escena tres personas: el que promete, el que acepta y el garante» (MdS 284; 107) ${ }^{9}$. La fuerza coactiva del orden jurídico es precisamente la garantía de los contratos privados. También las leyes son, conforme a una constitución republicana, promesas que nos hacemos recíprocamente los ciudadanos y el Estado. Los últimos garantes de estas promesas son lo jueces, y por eso el juez debe ser independiente de los poderes políticos ${ }^{10}$.

Si bien la constitución del Estado de Derecho se concibe como un contrato voluntario, hay que decir que «todos los hombres que pueden contraer relaciones jurídicas entre sí deben ingresar en este Estado» (MdS 306; 136). Es decir que, salir del estado de naturaleza jurídico es moralmente obligatorio y la constitución del orden civil es un fin que tiene en sí mismo un valor moral ( $M d S 307 ; 137-38)$. Se puede decir finalmente entonces que el contra-

${ }^{9}$ La abreviatura $M d S$ y la primera cifra entre paréntesis remiten I. Kant, Die Metaphisik der Sitten, Akademie Textausgabe, ed. cit., Bd. VI; la segunda cifra remite a la traducción española de A. Cortina y J. Conill: I. Kant, Metafísica de las Costumbres, Madrid, Tecnos, 1989.

${ }_{10} \mathrm{Cfr}$. A. Garapon, Le Gardien des Promesses. Justice et Démocracie, París, Editions Odile Jacob, 1996. 
to social es en este sentido un contrato moral y los ciudadanos deben respetar las leyes. Desde el punto de vista moral las leyes jurídicas son también moralmente vinculantes; la moralidad conlleva una predisposición interior a respetar también las leyes jurídicas, pero no a la recíproca: esta Gesinnung, o disposición moral, no puede ser producida por la ley y la sanción prevista en el sistema del Derecho positivo, y no es jurídicamente exigible. El derecho es, y debe permanecer exterior a la moralidad de las personas.

Habría que decir entonces que la comunidad ética está construida solamente sobre la base de la libre adhesión de la voluntad de sus miembros, a partir de las promesas recíprocas de fidelidad a los principios de la moralidad (como la promesa de obrar conforme a máximas que sean simétricas y de tratarnos como fines en sí, o de no instrumentalizar a nadie para nuestros propios fines). Pero estas promesas tienen que valer por sí mismas, sin garantías institucionales o jurídicas. Kant da a entender que en el trasfondo de estas promesas, y de la unión de la comunidad ética, está presente también un tercero, pero éste no aparece, sino que permanece como juez moral puro, que conoce desde el interior la conciencia moral del sujeto, pero es invisible y está desprovisto de toda fuerza real sancionatoria (o se abstiene de ejercerla).

Así como a partir del contrato social el individuo adquiere una identidad política y se transforma en ciudadano, la fidelidad a la palabra empeñada en esta otra promesa, y la pertenencia a esta comunidad ética, es constitutiva de la identidad moral de las personas. Esta misma idea ha sido explicitada por Paul Ricoeur de manera contemporánea, pero profundamente kantiana, como la fidelidad al sentido y al compromiso ilocucionario de la palabra, que hace posible la identidad de los significados y el propio funcionamiento del lenguaje, que es lo que constituye y define al hombre en cuanto tal, como el animal que tiene logos ${ }^{11}$.

Ya la Fundamentación de la Metafísica de las Costumbres concluía con la apelación a una fe racional que se abre en los confines de la filosofía práctica, y vislumbraba «el magnífico ideal de un reino de los fines en sí», al cual podemos ingresar y pertenecer como miembros en la medida en que nos conducimos en la vida práctica según máximas reconocidas y libremente asumidas que se fundan en el respeto de la ley moral. Este reino de los fines del que habla la Grundlegung puede considerarse como un primer esbozo de la idea de la comunidad ética universal de la Filosofía de la Religión. Kant se entusiasma con esta idea práctica y con la posibilidad de su realización aproximativa, como «lo que despierta en nosotros el más vivo interés por la moralidad». Porque sólo en este contexto donde la humanidad es tratada en la persona de cada uno como fin en sí misma, puede hacerse compatible la virtud con la felicidad, y en esto consiste el sumo bien, que no 1996. 
es lo mismo que la idea del Bien Supremo. En la «Dialéctica de la Razón pura práctica» de la Segunda Crítica, Kant aclara este concepto.

«El concepto del sumo bien (der Begriff vom höchsten Gute) entraña una ambigüedad que, si no es tenida en cuenta, puede dar lugar a disputas innecesarias. «Sumo» puede significar lo supremo (supremum) o también lo consumado (consumatum)... Que la virtud (en cuanto dignidad de ser feliz) constituya el bien supremo ha sido probado en la analítica. Más no por ello constituye todavía el bien completo y consumado en cuanto objeto de la capacidad desiderativa del ente racional finito, pues para ser tal se requiere también la felicidad... virtud y felicidad conjuntamente constituyen el sumo bien de un mundo posible» ${ }^{12}$.

Conforme a la lectura del texto de la Primera Crítica (A316-17, B37374) que he comentado en el apartado anterior, la idea del «sumo bien», como un mundo posible que trae a la presencia la plenitud consumada de una realidad que tiene en la historia una existencia solamente incohativa, puede interpretarse entonces como «la suma utopía», o el horizonte al cual nos abre solamente la dignidad de la vida moral. Esta idea ha dado lugar, sin embargo, a interpretaciones incorrectas. «La buena voluntad moral pura que no busca ninguna posible recompensa es la que nos hace dignos del sumo bien. Ésta era la doctrina que resplandecía en toda su pureza en la Grundlegung, y que habría sido corrompida en la Crítica de la Razón Práctica con esa concesión al eudemonismo en que venía a parar, según Schopenhauer, la pleitesía rendida al bien supremo... Pero, pensara Schopenhauer lo que pensara, Kant nunca concedió al eudemonismo que ser feliz fuera tan importante, éticamente hablando, como ser digno de la felicidad, una dignidad que los hombres solamente pueden alcanzar mediante el cumplimiento autónomo de su deber» ${ }^{13}$.

El reino de los fines ha sido interpretado a veces como un mundo inteligible, o nouménico, meramente pensado. En la Filosofía de la Religión, en cambio, es claro que se trata de algo realmente posible, y siempre ya realizado, aunque solamente en cierta medida de intensidad y de amplitud siempre todavía limitada. Esta limitación es el obstáculo principal de su posibilidad, porque en una pequeña comunidad de amigos morales puede tenerse una anticipación de ese ideal de la unión de la virtud con la felicidad, pero su realización es incompatible con un entorno social que vive en estado de naturaleza ético. Solamente en la universalidad de la comunidad ética puede alcanzarse realmente el sumo bien. Esta contrariedad es la que resonará también en el apotegma marxiano de que «no es posible el socialismo en un sólo país».

12 I. Kant, KpV, A 198-199, Akademie Textausgabe, Bd. V, ed. cit., cfr. también: Crítica de la Razón Pura, «Doctrina trascendental del método», cap. II: «El canon de la Razón Pura».

13 J. Muguerza, «Por un Kant aporético», en R. Aramayo, op. cit., 1992, p. 16. Sobre este debate, cfr. la exposición del autor del libro citado, pp. 88 ss. 
La utopía moral de Kant no debería comprenderse, sin embargo, como una utopía social, o política, que pudiera instituirse en un sistema reglado de manera concretista. Él se cuida muy bien de mantener la diferencia y la separación del ideal moral con respecto al ordenamiento jurídico-político. Probablemente Kant estaría de acuerdo en que si la meta esbozada de la historia se realizara en plenitud, la coactividad del sistema jurídico y la existencia misma del Estado serían superfluas. Pero esta situación no es de hecho previsible, y toda pretensión de planificar, o forzar el progreso moral mediante la coacción jurídica, es contradictoria, como ya se ha visto, y conduce a la ruina, tanto de la moral como del Derecho y la política. Está claro, sin embargo, que, si permanece vivo y es dinámico, el ideal moral habrá de operar permanentemente, por vía indirecta, desde la exterioridad de su lugar separado de toda institucionalidad, induciendo el mejoramiento de la calidad institucional del orden jurídico-político. Es admirable la sabiduría con que el realismo político de Kant ha moderado la veta de idealismo utópico de su pensamiento moral en sus escritos jurídico-políticos y de filosofía de la historia, y ha sabido equilibrar en su sistema un realismo de cuño hobbesiano con la apertura del horizonte de una utopía moral pensada como gradualmente realizable.

\section{Comunidad ética y sociedad civil}

La significación de este concepto de una comunidad ética construida solamente sobre la base de la identidad moral de la voluntad autónoma de sus miembros, e independiente del sistema jurídico-político del Estado, se redescubre y se puede valorar más adecuadamente recién ahora, en el contexto de los debates actuales de la filosofía política, a partir de la declinación del modelo del Estado moderno, del progresivo descentramiento de la institucionalidad política en la sociedad actual y del retorno de la sociedad civil, o de la recuperación de su autonomía frente al sistema político ${ }^{14}$.

Kant no tenía disponible otro término de comparación para diferenciar la idea de la comunidad ética y contraponerla al orden jurídico político, más que el modelo de la separación de la Iglesia y el Estado, que había sido un gran avance de la modernización frente al modelo de los Estados Teocráticos, o frente a la doctrina hobbesiana de la unidad indivisible y omniabarcante de la soberanía, que no admitía este tipo de asociación independiente del Estado porque la consideraba como un principio de sedición. La concepción kantiana profundiza, en cambio, la autonomía, la separación y la diferencia, excluyendo expresamente de la comunidad ética toda forma de insti-

${ }_{14}$ Mientras escribía estas páginas me ha llegado el anuncio de la aparición de un libro colectivo sobre el mismo tema, que no he podido consultar: M. Städtler (Herausgeber), Kants «Ethisches Gemeinwesen», Berlin, Akademie Verlag, 2005. 
tucionalidad que la asemeje a un Estado dentro del Estado y reproduzca en su interior el mismo tipo de relaciones de poder. Contrapone esta comunidad libre de la «iglesia invisible» universal, no solamente al Estado, sino también a las iglesias estatutarias, fuertemente estructuradas, divididas y establecidas con jurisdicciones particulares regionales o nacionales, de las que se diferencia tanto por su contenido puramente moral como también por su forma, que excluye toda institucionalidad jerárquica.

«Así, pues, una comunidad ética considerada como iglesia... no tiene propiamente ninguna constitución semejante según sus principios a la constitución política. Su constitución no es monárquica (bajo un Papa o Patriarca), ni aristocrática (bajo Obispos o Prelados), ni democrática (como las sectas de iluminados)... (762; 128).

La idea de esta comunidad universal se puede aproximar o parangonar con las ideas de la comunidad de los sabios, o de la trasnacional República de las Letras, de otros pensadores de la Ilustración que anticiparon la emergencia de nuevos sujetos sociales diferentes del sujeto colectivo de lo político encuadrado en las estructuras formales del Estado. Aunque estos nuevos sujetos no se plantean fines directamente políticos, en cuanto tienen presencia en el espacio público, adquieren también una relevancia política significativa y de primer orden. Los filósofos de la Ilustración no habían podido pensar todavía a la sociedad civil como un espacio público autónomo y diferenciado del Estado, como el lugar de las asociaciones voluntarias, y de las comunidades libres con las características de la idea de una comunidad ética, con sus redes cosmopolitas. En el lenguaje de la Filosofía Política de su época, «sociedad civil» y «Estado» eran todavía, simplemente, dos términos sinónimos. La diferencia y la contraposición de estos conceptos se hace reflexiva y ocupa un lugar sistemático en la filosofía política recién en el sistema filosófico de Hegel, y se desarrolla después, con orientaciones diversas, en el marxismo y en el liberalismo posterior.

Como en la utopía anarquista de una sociedad sin Estado, o de las comunidades libres de toda forma de dominación, la comunidad ética independiente del Estado y de la Iglesia, no solamente excluye las relaciones de poder, sino toda forma de institucionalidad y de regulación jurídica externa e interna. Podría pensarse que Kant había tenido en cuenta con clarividencia la antinomia que se plantea siempre entre un ideal de vida ética comunitaria y su institucionalización, sin la cual difícilmente se mantiene vivo y puede perdurar; pero al mismo tiempo, como ha ocurrido con la idea religiosa pura del fundador del cristianismo en las iglesias estatutarias, la institución y sus funcionarios (con la tendencia a la burocratización que le es connatural) deforman o reemplazan el espíritu originario de la comunidad por la positividad de un formalismo ritual y legal. Esta misma degradación o pérdida del espíritu aconteció con la idea republicana (o de la democracia) al institucio- 
nalizarse en el sistema jurídico del Estado moderno; más tarde sucedió también algo análogo con los ideales y valores socialistas, ahogados en las estructuras de los aparatos del llamado socialismo real y en el totalitarismo del Estado soviético.

Pero Kant se había dejado instruir también por el realismo político de Thomas Hobbes sobre la necesidad sin alternativa de correr los riesgos de la institución del poder soberano y de un sistema jurídico-político que garantice la paz social y evite el retroceso al temible estado de naturaleza hobbesiano de la situación de guerra civil generalizada. La estabilización del Estado de Derecho, y la mayor complejidad de la sociedad y del Estado en el siglo XVII, le permiten pensar a Kant, sin embargo, al mismo tiempo la idea de comunidades libres de existencia pública que mantienen su exterioridad e independencia dentro del sistema jurídico político. La dinámica de la comunidad ética de la sociedad civil y su presencia en el espacio público habrá de jugar un papel fundamental también en la regeneración de las propias instituciones, sean éstas estatales o eclesiásticas. Sin esta exterioridad crítica y ética toda institucionalidad tiende a la esclerosis, y ninguna regeneración es posible.

Si preguntamos, finalmente, cómo es posible la reproducción y la estabilización de una comunidad con estas características, sin adoptar una forma de institucionalidad, ya no encontramos en el texto kantiano indicaciones reales y concretas más allá de las mencionadas apelaciones simbólicas al lenguaje teológico-religioso. Con el concepto de la comunidad ética el viejo Kant había planteado con gran clarividencia la idea de un espacio posconvencional y cosmopolita de la vida moral autónoma y de la religión, que ya se insinuaba en la realidad de su propia época. Este pensamiento apuntaba a un tema central, no solamente para la vida moral, sino también para la vida política después de la constitución formal del Estado moderno. El planteamiento kantiano ha dejado abiertas una gran cantidad de cuestiones en este terreno, las cuales están llegando a ser hoy preguntas centrales en la filosofía contemporánea cuando se contrapone la exterioridad y la dinámica de una sociedad civil que ya no es Estado-céntrica frente al sistema de las instituciones jurídico-políticas, y cuando se piensa lo político mismo y la democracia en su sentido originario, más acá de las estructuras y los procedimientos formales de las instituciones estatales y para-estatales (como los partidos políticos). 